\title{
Revista Brasileira de Enfermagem REBEn Aplicação do Processo de Enfermagem:
estudo de caso com uma puérpera
}

\author{
The Nursing Process implementation: a post-partum case study \\ Implementación del Proceso de Enfermería: un estúdio de caso con una puérpera
}

\begin{abstract}
Albertisa Rodrigues Alves
Enfermeira. Aluna do Curso de Mestrado Acadêmico Cuidados Clínicos em Saúde (CMACCLIS) da Universidade Estadual o Ceará (UECE), Fortaleza, CE.
\end{abstract}

Edna Maria Camelo Chaves

Enfermeira. Mestre em Enfermagem. Enfermeira do Hospital Geral de Fortaleza, CE.

\section{Maria Célia de Freitas}

Enfermeira. Doutora em Enfermagem. Curso de Mestrado Acadêmico Cuidados Clínicos em Saúde (CMACCLIS) da Universidade Estadual o Ceará (UECE), Fortaleza, CE.

\section{Ana Ruth Macedo Monteiro}

Enfermeira. Doutora em Enfermagem. Curso de Mestrado Acadêmico Cuidados Clínicos em Saúde (CMACCLIS) da Universidade Estadual o Ceará (UECE), Fortaleza, CE.

\section{RELATO DE EXPERIÊNCIA}

\section{RESUMO}

O estudo objetivou implementar o processo de enfermagem, no cuidado a uma puerpera portadora de miocardiopatia periparto depois de parada cardiorrespiratória. Realizamos um estudo de caso clínico, em uma unidade intensiva do Município de Fortaleza, no período de setembro a outubro de 2005. Os dados foram obtidos após avaliação para elaboração dos diagnósticos NANDA taxonomia II, julgamento clínico, intervenção e metas. Os diagnósticos de enfermagem encontrados foram: comunicação verbal prejudicada, débito cardíaco diminuído, padrão respiratório ineficaz, volume excessivo de líquidos, diarréia, mobilidade física prejudicada e déficit no autocuidado. Ressaltamos a importância do processo como foco do trabalho do enfermeiro na clínica, na perspectiva de favorecer o retorno dos pacientes ao seu contexto familiar, bem como permitir credibilidade do trabalho de enfermagem.

Descritores: Diagnóstico de enfermagem; Enfermagem; Processo de enfermagem.

\section{ABSTRACT}

The study aimed at implementing the nursing process for a post-partum woman with cardiomyopathy after cardiorespiratory arrest. We conducted a clinical case study, in an intensive care unit of Fortaleza, Ceará, Brazil, in the period from September to October, 2005. The data were obtained after evaluation for elaboration of Nursing Diagnoses according to NANDA Taxonomy II, clinical judgment, intervention and goals. The nursing diagnoses found were: impaired verbal communication, decreased cardiac output, inefficient respiratory pattern, excessive volume of fluids, diarrhea, impaired physical mobility and deficit in selfcare. We highlighted the importance of the process as focus of the nurse's work in the clinic, in order to favor the patient's return to his family context as well as give credibility to the nurse's job. Descriptors: Nursing diagnosis; Nursing; Nursing process.

\section{RESUMEN}

El estudio objetivó implementar el proceso de enfermería, en el cuidado a una parturienta portadora de miocardiopatía peripato después de parada cardiorrespiratoria. Realizamos un estudio de caso clínico, en una Unidad Intensiva del Municipio de Fortaleza, en el período de septiembre a octubre de 2005. Los datos fueron obtenidos después de evaluación para la elaboración de los diagnósticos NANDA taxonomia II, juicio clínico, intervención y metas. Los diagnósticos de enfermería fueron: comunicación verbal perjudicada, débito cardíaco diminuido, padrón respiratorio ineficaz, volumen excesivo de líquidos, diarrea, mobilidad física perjudicada y déficit en el auto cuidado. Resaltamos la importancia del proceso como foco del trabajo del enfermero en la clínica, en la perspectiva de favorecer el retorno de los pacientes al su contexto familiar y también permitir credibilidad del trabajo de enfermería. Descriptores: Diagnóstico de enfermería; Enfermería; Proceso de enfermería.

Alves AR, Chaves EMC, Freitas MC, Monteiro ARM. Aplicação do Processo de Enfermagem: estudo de caso com uma puérpera. Rev Bras Enferm 2007 maio-jun; 60(3):344-7.

\section{INTRODUÇÃO}

A implementação da sistematização da assistência de enfermagem continua sendo no cotidiano da enfermagem um desafio, pois esta requer planejamento de ações e resgate de conteúdos relacionados à Fisiologia, Patologia e Farmacologia. Em alguma situação, na demanda do serviço, requer sua efetivação. Faz-se necessário a elaboração de um plano de cuidado que contemple as necessidades do paciente que se encontram afetadas.

O enfermeiro ao pensar no processo, deve fazer uma abordagem centrada não apenas nas necessidades fisiológicas, mas nos aspectos biopsicossocial, espiritual e cultural(1).
Submissão: $05 / 06 / 2006$

Aprovação: $02 / 01 / 2007$ 
A enfermagem, especialmente a partir dos anos 50 do século $X X$, busca desenvolver um corpo de conhecimentos próprios no sentido de sistematizar e organizar sua prática e seus cuidados, de modo a favorecer uma assistência baseada não somente na dimensão biológica do ser humano, mas essencialmente na compreensão do homem como ser social e ator principal no processo saúde-doença, seja no âmbito hospitalar, seja na saúde coletiva.

Diversos modelos teóricos são desenvolvidos e aplicados na prática de cuidado do enfermeiro da área hospitalar, no intuito de encontrar respostas a problemas de saúde e de doença, em que o modelo clínico essencialmente biomédico não da conta de resolver. Buscar integrar os conhecimentos das ciências da natureza com das ciências sociais e compreensivas, objetivando assistir o ser humano dentro de uma perspectiva ampla e integral, pode ser um novo desafio a ser percorrido por todos os que diretamente ou indiretamente estão preocupados com as condições de saúde e de doença da humanidade.

Neste sentido, relativamente aos modelos conceituais, especialmente na enfermagem, a teoria que mais se adequou a condições tão complexas e dinâmicas, e que se tenta implementar na maioria dos hospitais brasileiros, percebendo o ser humano sob vários aspectos, de forma holística e integral, dentre os diferentes referenciais foi a Teoria das Necessidades Humanas Básicas (NBH) de Maslow, que fundamentará a elaboração do estudo de caso clínico ora apresentado(2)

A Teoria das NHB engloba a Teoria da Motivação Humana de Maslow (1970) e de João Mohana (1964) que classifica as necessidades humanas em psicobiológicas, psicosociais e psicoespirituais, sendo conhecida como uma das mais importantes teorias de motivação humana. Para ele, as necessidades dos seres humanos obedecem a uma hierarquia, ou seja, uma escala de valores a serem transpostos, no momento em que o indivíduo realiza uma necessidade, surge outra em seu lugar, exigindo sempre que as pessoas busquem meios para satisfazê-la ${ }^{(2)}$.

A teoria se apóia e engloba leis gerais que regem os fenômenos universais, tais sejam, como exemplo: a lei de equilíbrio ou homeodinâmica, em que todo universo se mantém por processos de equilíbrio dinâmico entre seus seres; a lei da adaptação, pela qual todos os seres do universo interagem com seu meio externo buscando sempre formas de ajustamento para se manterem em equilíbrio; a lei do holismo, sendo o universo um todo, o ser humano um todo, a célula um todo, ou seja, esse todo não é meramente a soma das partes constituintes de cada $\operatorname{ser}^{(3)}$.

No cotidiano do enfermeiro intensivista o processo de enfermagem enseja caminhos, permitindo uma qualificação de cuidados, visto que ela planejara ações, priorizando as respostas humanas no processo saúde doença. Ela considera o ser humano a partir das suas necessidades básicas, permitindo a elaboração de ações sistematizadas de enfermagem, fundamentando a assistência prestada.

Dessa forma, o estudo teve como objetivo implementar o processo de enfermagem, no cuidado a uma puérpera portadora de miocardiopatia periparto e encefalopatia hipóxica após parada cardiorrespiratória (PCR) internada em uma instituição pública.

\section{METODOLOGIA}

Trata-se de um estudo de caso clínico, utilizando o processo de enfermagem nas suas fases de histórico, diagnóstico de enfermagem, planejamento, intervenção e avaliação dos resultados. Foram utilizados a teoria NHB e o processo de enfermagem.

$O$ estudo de caso pode ser definido como um estudo delimitado com a exploração de um sistema, obtido a partir de uma coleta de dados detalhada, envolvendo varias fontes de informação(4). Estes são apropriados para serem aplicados na assistência direta de enfermagem, com a finalidade de realizar um estudo profundo dos problemas e necessidades do paciente, família e comunidade, com a possibilidade de elaborar estratégias para solucionar ou reverter os problemas encontrados ${ }^{(5)}$.

No preenchimento do histórico, realizamos o levantamento dos dados por meio do exame físico e consulta ao prontuário, a fim de coletar dados para identificar os diagnósticos de enfermagem. Na implementação do histórico, não foi possivel realizar anmenese pelo nível de consciência da paciente $e$ ausência de representantes da família.

O diagnóstico de enfermagem é a segunda fase do processo, em que pelos dados coletados, são identificados os fenômenos de enfermagem. Estes são apontados por meio da identificação das NBH afetadas e do julgamento clínico mediante esta investigação.

Na identificação dos diagnósticos de enfermagem utilizamos o julgamento clínico e o raciocínio diagnóstico estabelecido por Risner ${ }^{(6)}$. A fase inicial compreende a análise e a síntese dos dados obtidos a partir do exame físico e entrevista, enquanto que a fase seguinte (ou fase 2), caracteriza-se pelo estabelecimento do diagnóstico propriamente dito.

No período de análise, entendida como a separação dos dados e exame crítico por parte do examinador/ diagnosticador, este percorre dois passos: categorização dos dados e identificação dos indicativos divergentes ou lacunas. Durante a categorização dos dados ou da sua organização lógica, dos mesmos, o enfermeiro pode empregar diferentes modelos conceituais ou concepções teóricas que o subsidiem. Aidentificação de dados incompletos ou das lacunas evidencia que estes devem ser revisados cuidadosamente, evitando assim erros diagnósticos.

Ainda na fase inicial, o enfermeiro realiza a síntese dos elementos encontrados, ou seja, é o processo de raciocínio no qual a conclusão é diretamente obtida das proposições dadas e princípios estabelecidos. Nesta fase serão desenvolvidas as seguintes atividades: agrupamento das evidências em padrões, de acordo com o referencial teórico escolhido, o que facilitará o raciocínio para o julgamento clínico; comparação dos padrões a teorias, modelos, normas e conceitos; inferências ou hipóteses, sendo a fase de julgamento clínico propriamente dita; proposição, causas ou relação é a conclusão do período de síntese, sendo identificados os fatores que influenciam e contribuem para as alterações inferidas.

A fase 2 ou estabelecimento do diagnóstico propriamente dito, é definida estruturalmente pelo título do diagnóstico ou problema de saúde inferido pelo enfermeiro, pelo fator relacionado ou etiológico e pelas características definidoras, que são os dados objetivos e subjetivos agrupados a evidenciarem os diagnósticos de enfermagem.

Na identificação dos diagnósticos de enfermagem, utilizamos o julgamento clínico e o raciocínio diagnóstico, estabelecido nas seguintes etapas: agrupamentos dos dados e comparação dos padrões a teorias e normas ${ }^{(6)}$. O julgamento clínico e o conhecimento do enfermeiro aplicado a qualquer tratamento têm como finalidade otimizar os resultados obtidos pelo paciente ${ }^{(7)}$.

Para a elaboração dos diagnósticos empregamos a North American Nursing Diagnosis Association (NANDA), uma vez que estes representam a base para seleção de intervenções e resultados terapêuticos ${ }^{(8)}$.

Após conhecimento dos diagnósticos de enfermagem, foram elaboradas intervenções com esta definição: é o roteiro diário (ou aprazado) que coordena a ação da equipe de enfermagem nos cuidados adequados ao atendimento das necessidades básicas e específicas do ser humano ${ }^{(3)}$.

O local da implementação do processo foi à unidade de terapia intensivoadulta de um hospital público no município de Fortaleza-CE, no período de setembro a outubro de 2005. O sujeito da pesquisa é uma senhora de 29 anos, dois filhos, casada, com segundo grau completo e que se encontrava há 60 dias internada.

O projeto foi aprovado pelo Comitê de Ética em Pesquisa da Universidade Estadual do Ceará, conforme resolução 196/96, do Conselho Nacional de Saúde, sobre pesquisas em seres humanos.

\section{APRESENTAÇÃO DO ESTUDO DE CASO}

Mulher, 29 anos, casada, 2 filhos, sendo um recém-nascido de 25 dias, admitida no dia 09/08/2005, às 20h, proveniente da emergência em franca insuficiência respiratória, a qual foi imediatamente intubada na unidade de terapia intensiva- adulto e instalada ventilação mecânica.

Durante a intubação, houve eliminação de secreção espumosa pelo tubo, 
sugestivo de EAP (edema agudo de pulmão). Os diagnósticos médicos foram: miocardiopatia periparto eEAP hipertensivo. Evoluindo satisfatoriamente da insuficiência respiratória, foi iniciada pela manhã o desmame da ventilação mecânica no dia 11/08/2005. Ás $15 \mathrm{~h}$ desse dia foi extubada, permanecendo com suporte de oxigênio através da máscara de venturi, por cerca de 2 horas. Por volta das $17 \mathrm{~h}$, apresentou pico hipertensivo com EAP, que não respondeu a VMNI (ventilação mecânica não invasiva) , e novamente foi intubada e reinstalada VM (ventilação mecânica) .Apresentou PCR (parada cardiorrespiratória) com FV (fibrilação ventricular) a qual foi desfibrilada com 200 joules e procedidas manobras de reanimação por 18 minutos. Após reanimação, realizada cateterização da artéria pulmonar. Seguindo sob sedação e analgesia, evoluiu pós PCR com mioclonias, convulsão, pupilas midriátidas e pouco reagentes. A avaliação do neurologista concluiu: encefalopatia hipóxica severa, coma vigil, déficit motor dos quatro membros e prognóstico muito reservado com respeito à recuperação cerebral. Encontrase em 14/09/2005 traqueostomizada, sob ventilação mecânica, no módulo SIMV (ventilação mandatória intermitente sincronizada), acordada, mas não interativa com o ambiente, responsiva aos estímulos dolorosos, escala de coma de Glasgow, totalizando nove (8) pontos, sendo: abertura ocular (4), resposta verbal (1), e resposta motora (3). Pupilas isocóricas e fotoreagentes. Apresentou convulsão. Presença de roncos bilaterais difusos à ausculta pulmonar, e eliminação de secreções traqueobrônquicas sanguinolenta, por ocasião das aspirações traqueobrônquicas, sugestivas de trauma. Hoje 22/ 09 houve tentativa de desmame da ventilação mecânica sem sucesso. Após medidas terapêuticas da equipe multiprofissional, paciente permanece em sincronia com ventilação artificial, com boa expansibilidade torácica. Ritmo cardíaco regular, sinusal, com sobrecarga das câmaras esquerda. Pulsos periféricos palpáveis, rede venosa pouco visível, dissecção venosa em veia jugular externa. Edema de membros superiores e inferiores. Sinal de cacifo positivo (+++). Turgor cutâneo diminuído, pele hidratada e íntegra. Abdomes globosos, flácidos, com fígado palpável. Com dieta por sonda enteral $1416 \mathrm{kcal} / 24 \mathrm{horas}$. Presença de fezes diarréicas, diurese espontânea nas fraldas. Restrita no leito. Com sangramento transvaginal. Presença de leite. Fazendo uso de antimicrobiano, diurético, anticonvulsivante, insulina, anticoagulante.

Os dados apresentados trazem os $\mathrm{DE}$ as intervenções de enfermagem propostas e as metas. A elaboração de diagnósticos de enfermagem é um processo complexo que envolve o comportamento humano relacionado à saúde ${ }^{(9)}$.

As atividades propostas foram uma junção das atividades realizadas pelas enfermeiras da referida instituição onde o estudo foi desenvolvido e das propostas adotadas pela NIC. Esta classificação é ampla e padroniza as intervenções realizadas pelas enfermeiras, podendo ser utilizada em todo 0 âmbito da saúde ${ }^{(10)}$.

As avaliações da eficácia das intervenções serviam de base para justificar a sua manutenção, ou realizar as alterações que fossem necessárias, de acordo com os resultados propostos pela NOC, utilizando-se a escalas codificada, que permite representar cada um dos elementos taxonômicos. Os resultados definem um estado do paciente em um determinado momento ou tempo e serve como indicador para avaliar a melhora ou piora do estado clínico. Aestrutura de códigos inclui os domínios, as classes, os resultados, os indicadores de cada resultado, as escalas de medida e os escores reais registrados pelos usuários $(\mathrm{NOC})^{(7)}$.

Apresentamos os DE as intervenções propostas pela NIC e os resultados de acordo com a codificação da NOC.

1. DE -Comunicação verbal prejudicada, relacionada à alteração do sistema nervoso central e traqueostomia.

1.1Intervenções / atividades (NIC) - Melhora da comunicação: déficit da fala

1.1.1Usar recurso alternativo para estabelecer comunicação com o paciente; papel, caneta e estímulos de linguagem.
1.1.2 Falar pausadamente em voz alta em pé próximo do ouvido da paciente.

1.1.3 Falar olhando para paciente, observando as reações.

1.1.4 Evitar baixar a voz no final da frase.

1.2Resultado (NOC) - Comunicação: capacidade de recepção.

Indicador-interpretação de linguagem não verbal. Extremamente comprometida - 1

2. Débito cardíaco diminuído relacionado à contratilidade alterada

2.1Cuidados cardíacos

2.1.1Monitorizar ritmo e freqüência cardíaca de $2 / 2$ horas.

2.1.2 Reconhecer as alterações de débito cardíaco.

2.1.3 Documentar arritmias.

2.1.4 Monitorar pressão arterial, pulso, temperatura, padrão respiratório de $2 / 2$ horas.

2.15 Monitorar oxímetro de pulso contínuo.

2.2-Estado dos sinais vitais.

Indicadores - temperatura, pulso radial, freqüência respiratória, pressão arterial sistólica e pressão arterial diastólica.

Desvio moderado em relação aos parâmetros esperados - 3

3. Padrão respiratório ineficaz relacionado à disfunção neuromuscular.

3.1 Ventilação mecânica

3.11 Monitorar fadiga muscular respiratória contínua.

3.1.2 Monitorizar rotineiramente os parâmetros do ventilador.

3.1.3 Manter gases umidificados e aquecidos.

3.1.4 Verificar regularmente as conexões do ventilador

3.1.5 Esvaziar a água condensada nos reservatórios, quando necessário.

3.1.6 Interromper alimentação por sonda enteral durante a aspiração e por 30 a 60' antes da intervenção de outros profissionais

3.2 - Estado respiratório-levemente comprometido.

Indicadores

Expansibilidade simétrica do tórax; aspiração das vias aéreas; sons auscultatórios dentro do padrão de normalidade (DPNE).

4. Desobstrução ineficaz de vias aérea relacionada a secreções retidas e presença de via aérea artificial.

4.1.Aspiração de vias aéreas.

4.1.1 Aspirar secreções traqueobrônquicas de acordo com a necessidade.

4.1.2 Realizar toillete brônquica.

4.1.3 Monitorizar saturação de oxigênio.

4.2.Estado respiratório: desobstrução de vias aéreas.

Indicadores

Taxa respiratória DPNE; ritmo respiratório dentro do padrão esperado

(DPE) livre de sons respiratórios adventícios.

Levemente comprometidas -4 .

5. Risco para infecção relacionado a procedimentos invasivos e exposição ambiental a patógenos aumentada

5. Controle de infecção

5.1.1 Lavar as mãos antes e após cada atividade de cuidado com o paciente.

5.1.2 Monitorizar a temperatura a cada duas horas.

5.1.3 Realizar curativo com película transparente do acesso venoso central a cada 07 dias ou quando necessário.

5.1.4 Renovar curativo da traqueostomia e fixação diariamente.

5.1.5 Manusear de forma asséptica de todas as linhas venosas e aéreas.

5.Conhecimento: controle de infecção.

Indicadores

Descrição de práticas que reduzem a transmissão; descrição de sinais e sintomas; descrição de procedimentos de exame.

Extensivo - 5

6. Volume excessivo de líquidos relacionado a mecanismos reguladores comprometidos. 
6.1.1. Controle do balanço hídrico.

6.1.2 Realizar balanço hídrico a cada 06 horas.

6.1.3 Monitorar pressão arterial, freqüência respiratória, freqüência cardíaca a cada duas horas.

6.1.4 Monitorar cor, quantidade, gravidade específica da diurese.

6.1.5 Observar edema.

6.1.6 Monitorizar medicação intravenosa contínua

6.2 Hidratação.

Indicadores

Hidratação da pele; membranas e mucosas hidratadas; edema periférico não presente, hematócrito DPNE.

Levemente comprometidas - 4

7. Diarréia relacionada a fatores situacionais e fisiológicos.

7.1 Diarréia relacionada a fatores situacionais e fisiológicos.

7.1.1 observar regularmente o turgor da pele.

7.1.2 Realizar higiene após evacuações e renovar fraldas.

7.1.3 Monitorar a pele na área perineal na busca de irritação e ulceração.

7.1.4 Manter dieta por bomba de infusão continua.

Avaliar o perfil medicamentoso

7.2 Eliminação intestinal.

Indicadores

Fácil passagem das fezes; ingestão de líquidos adequados; fezes livres de muco; fezes livres de sangue.

8. Mobilidade física prejudicada relacionada a prejuízos sensórios - perceptivos.

8.1 Posicionamento

8.1.1 Realizar mobilização no leito de $2 / 2$ horas

8.1.2 Colocar sob colchão articulado ou cama terapêuticos.

8.1.3 Explicar a paciente durante a mobilização no leito.

8.1.4 Monitorar, levando em conta o alinhamento correto do corpo.

8.2.Posicionamento do corpo: auto iniciado.

Indicador - de deitado a deitado.

Dependente não participa - 1

9. Déficit no autocuidado relacionado a prejuízo perceptivo e cognitivo.

9. 1 Higiene

9.1.1 Banhar o paciente em água com temperatura confortável.

9.1.2 Realizar medidas de higiene, cuidado com períneo e genitália.

9.1.3 Realizar higiene ocular e oral

9.2 Atividades da vida diária.

Indicadores
Alimentar-se; vestir-se; higiene e banho.

Dependente não participa-1.

As necessidades são universais, comuns a todos os seres humanos. $O$ que varia de um indivíduo para o outro é a sua manifestação e a maneira de satisfazê-la e atendê-la. Os fatores que interferem na manifestação de individualidade são idade, sexo, cultura, escolaridade, ciclo de saúde e fatores socioeconômicos. Encontramos no padrão de resposta humano as necessidades psicobiológicas e sociais afetadas ${ }^{(2)}$.

Percebemos que havia uma coerência entre as nossas atividades cotidianas e a linguagem apresentada na NIC e NOC, sendo, portanto, facilitada a compreensão e articulação das proposições e atividades diárias por considerarmos verdadeiras e coerentes com a nossa vivência clínica e por estar em concordância com a NIC, embora não esteja escrita "ipsis litteiss". Na referida instituição a SAE é aplicada pelos enfermeiros das unidades de terapia intensiva.

A utilização do modelo conceitual possibilitou a instrumentalização da assistência na prática, favorecendo o alcance de metas e padrões mínimos no cuidado prestado ao cliente hospitalizado ${ }^{(11)}$.

Concluída a coleta dos dados podemos chegar aos diagnósticos com as características definidoras e os fatores facilitadores no processo cotidiano. Os diagnósticos primários são aqueles que, se forem priorizadas as intervenções de enfermagem, poderão desencadear melhoras em outras situações ${ }^{(12)}$.

\section{CONSIDERAÇÕES FINAIS}

A aplicação do processo de enfermagem neste estudo possibilitou aos enfermeiros no campo prático desenvolver uma assistência pautada no conhecimento científico com a utilização da NANDA, NIC e NOC.

Portanto, acrescentamos que 0 uso da linguagem padronizada não distancia a nossa prática, pois el a facilita o processo de comunicação desejável, evitando uma interpretação duvidosa. Ressaltamos que o desenvolvimento e a aplicação dessa tecnologia leve de enfermagem ajuda a desenvolver 0 conhecimento, favorecendo uma prática efetiva, eficaz, minimizando barreiras.

Aincorporação dos diagnósticos de enfermagem proposta pela NANDA taxonomia II NIC e NOC propiciaram a elaboração de um modelo contemplando as necessidades biológicas que foram as mais afetadas.

Vale ressaltar a importância do processo como foco do trabalho do enfermeiro na clínica, na perspectiva de favorecer o retorno dos pacientes ao seu contexto familiar e de trabalho o mais precocemente possível, bem como permite credibilidade do trabalho de enfermagem.

\section{REFERÊNCIAS}

1. Ribeiro MNA, Ximenes LB, Araújo TL. O cuidado de enfermagem na síndrome de Stevens - Johnson. Pediatria Atual 2000;13(10): 44-50.

2. Leopardi MT. Teorias em enfermagem: instrumentos para a prática. Florianópolis (SC): Papa Livros; 1999.

3. Horta WA. Processo de Enfermagem. São Paulo (SP): EPU; 1979.

4. Ludke $M$, André M. Pesquisa em educação - abordagens qualitativas. São Paulo (SP): EPU; 1986.

5. Galdeano LE, Rossi LA, Zago MMF. Roteiro instrucional para elaboração de um estudo de caso clínico. Rev Latino-am Enfermagem 2003;11(3):371-5.

6. Risner PB. Diagnosis: analysis and synthesis of data. In: Griftith K, Cristensen PJ. Nursing Process: application of theories frameworks and models. $2^{\text {nd }}$ ed. Saint Louis $(M I):$ Mosby; 1986.
7. Johnson M, Maas M, Moorhead S. Classificação de Resultados de Enfermagem. $2^{\mathrm{a}}$ ed. Porto Alegre (RS): Artmed; 2004.

8. North American Nursing Diagnoses Association (NANDA). Diagnósticos de Enfermagem: definições e classificação 20032004. Porto Alegre (RS): Artmed; 2005.

9. Luney M. Pensamento crítico e diagnóstico de enfermagem estudo de caso e análise. Porto Alegre (RS): Artmed; 2004.

10. McCloskey JC, Bulechek GM. Classificação das intervenções de enfermagem. $3^{\mathrm{a}}$ ed. Porto Alegre (RS): Artmed; 2004.

11. Reppetto MA, Souza MF. Avaliação da realização e do registro da sistematização da assistência de enfermagem (SAE) em um hospital universitário. Rev Bras Enferm 2005;58(3):325-9.

12. Sena $\mathrm{CA}$, Carvalho EM, Ruffino MC. Estratégias de implementação do processo de enfermagem para uma pessoa infectada pelo HIV. Rev Latino-am Enfermagem 2001;9(1):27-38. 